\title{
Neurosurgery and prognosis in patients with radiation-induced brain injury after nasopharyngeal carcinoma radiotherapy: a follow-up study
}

Yi Li ${ }^{1,2+}$, Xiaolei Shi ${ }^{1,2}$, Xiaoming Rong ${ }^{1,2}$, Ying Peng ${ }^{1,2}$ and Yamei Tang ${ }^{1,2^{*+}}$

\begin{abstract}
Background: Radiotherapy is the standard radical treatment for nasopharyngeal carcinoma (NPC) and may cause radiation-induced brain injury (RI). Treatment for RI remains a challenge. We conducted this study to investigate the indications of neurosurgery, operation time and prognosis of patients with RI after NPC radiotherapy who underwent neurosurgical management.

Methods: This was a follow-up study between January 2005 and July 2011. Fifteen NPC cases of RI who underwent neurosurgery were collected. Brain Magnetic resonance imaging (MRI), surgery and histology were studied. The outcome was assessed by LENT/SOMA scales and modified Rankin scale.

Results: Brain lesion resection (86.7\%) was more common than decompressive craniotomy (13.3\%). According to LENT/SOMA scale before and six months after surgery, 13 of 15, 12 of 15, 14 of 15, and 14 of 15 cases showed improvement at subjective, objective, management and analytic domains, respectively. 12 of 15 patients showed improvement of modified Rankin scale after surgery. Three patients who underwent emergency surgery showed significant improvement (average score increment of 2, 2.7, 2.7, 3 and 2 at LENT/SOMA scale subjective, objective, management, analytic, and modified Rankin scale, respectively), as compared with 12 cases underwent elective surgery (average score increment of 1, 1, 1.4, 1.8 and 1 at LENT SOMA scale subjective, objective, management, analytic, and modified Rankin scale, respectively).
\end{abstract}

Conclusions: Neurosurgery, including brain necrotic tissue resection and decompressive craniotomy, improves the prognosis for RI patients, especially for those with indications of emergency surgery.

Keywords: Radiotherapy, Nasopharyngeal carcinoma, Radiation-induced brain injury, Neurosurgery

\section{Introduction}

Nasopharyngeal carcinoma (NPC) is the third most common malignant tumor in men in certain regions of East Asia, with an incidence of 15 to 50 per 100,000 [1]. Radiotherapy is the standard radical treatment for NPC and has produced long-term effects. However, it injuries the normal brain tissue and accounts for several severe

\footnotetext{
* Correspondence: yameitang@hotmail.com

${ }^{\dagger}$ Equal contributors

'Department of Neurology, Sun Yat-Sen Memorial Hospital, Sun Yat-Sen University, Guangzhou, China

${ }^{2}$ Key Laboratory of Malignant Tumor Gene Regulation and Target Therapy of Guangdong Higher Education Institutes, Sun Yat-sen University, Guangzhou, China
}

delayed sequelae, including radiation-induced brain injury (RI) [2]. At the time patients present with clinical symptoms of RI, the brains have already suffered with irreversible damage.

Treatment for RI remains a challenge. Although rehabilitation and medication, e.g. corticosteroids, dehydrants, anticoagulants and neuroprotective agents, were the mainstay of treatment [3,4], some cases of RI showed exacerbation. Cerebral lesions in these cases might show as mass effect, necrosis, foci of calcification, encephalomalacia, and/or porencephaly [5,6], and these changes were reserved as signs of neurosurgical management [7]. In this study, we prospectively analyzed the indications, operation time and 
Table 1 Demographic Data of RI patients underwent surgery ( $N=15$, in years)

\begin{tabular}{|c|c|c|c|c|c|c|c|c|c|}
\hline Case & Age & Gender & $\begin{array}{l}\text { Interval }^{1} \\
1 \text { (year) }{ }^{1}\end{array}$ & $\begin{array}{l}\text { Interval } 2 \\
\text { (month) }\end{array}$ & $\begin{array}{l}\text { Radiation } \\
\text { dose (Gy) }\end{array}$ & Radiation field & Reirradiation & $\begin{array}{l}\text { Follow-up } \\
\text { months }\end{array}$ & Clinical outcome \\
\hline 1 & $53 y$ & M & 0.5 & 144 & 68 & Faciocervical & $\mathrm{N}$ & 52 & Survival \\
\hline 2 & $57 y$ & M & 5 & 36 & 76 & Faciocervical & $\mathrm{N}$ & 39 & Survival \\
\hline 3 & $57 y$ & M & 7 & 36 & 70 & Preauricular & $\mathrm{N}$ & 32 & Survival \\
\hline 4 & $60 y$ & M & 2 & 3 & 70 & Faciocervical & $\mathrm{N}$ & 25 & Died \\
\hline 5 & $28 y$ & M & 3 & 10 & 68 & Preauricular & N & 30 & Survival \\
\hline 6 & $58 y$ & $\mathrm{~F}$ & 13 & 12 & 66 & Faciocervical & $\mathrm{N}$ & 8 & Died \\
\hline 7 & $48 y$ & M & 3 & 5 & $70+68$ & Faciocervical & Y & 6 & Survival \\
\hline 8 & $57 y$ & $\mathrm{~F}$ & 5 & 12 & 72 & Faciocervical & N & 60 & Survival \\
\hline 9 & $42 y$ & M & 4 & 11 & $68+68$ & Faciocervical & Y & 11 & Survival \\
\hline 10 & $53 y$ & M & 4 & 11 & $68+68$ & Faciocervical & Y & 13 & Survival \\
\hline 11 & $42 y$ & M & 2 & 24 & 70 & Preauricular & $N$ & 41 & Survival \\
\hline 12 & $65 y$ & M & 7 & 12 & 70 & Preauricular & $\mathrm{N}$ & 27 & Survival \\
\hline 13 & $51 y$ & M & 3 & 36 & 68 & Faciocervical & $\mathrm{N}$ & 71 & Survival \\
\hline 14 & $48 y$ & M & 2 & 24 & 70 & Faciocervical & N & 20 & Survival \\
\hline 15 & $50 y$ & M & 5 & 22 & 74 & Faciocervical & $\mathrm{N}$ & 22 & Survival \\
\hline
\end{tabular}

${ }^{1}$ Interval between radiation and diagnosis of RI (for the patients who underwent reirradiation, this was the interval between reirradiation and diagnosis of RI).

2 Interval between diagnosis of RI and surgery.

prognosis of RI patients after NPC radiotherapy who underwent neurosurgical management.

\section{Materials and methods}

Adult NPC patients with radiation-induced brain injury after radiotherapy who underwent neurosurgery between January 2005 and July 2011 were prospectively analyzed. At least six months follow-up was performed.

\section{Patients}

All patients were inpatients at Sun Yat-Sen Memorial Hospital in Guangzhou, China. Inclusion criteria were defined as follow: (1) a history of radiotherapy after NPC; (2) a diagnosis of RI based on magnetic resonance imaging (MRI), with or without neurological deficits; and (3) an exclusion of cancer relapse, metastases, other malignances, neurovascular disease, demyelinating disease, or other diseases of the nervous system. The operation indication of the patients was evaluated by two neurological surgeons and two neurologists. The institutional ethics review board of Sun Yat-Sen Memorial Hospital granted approval for the study (No. 审伦备 [1] 号). Informed consents were obtained from all involved subjects.

The following data were recorded:

Demographics: Age, sex, post-radiotherapy intervals (interval between radiation and diagnosis of RI, and interval between diagnosis of RI and neurosurgery), radiation dose, radiation field, and reirradiation.
Clinical examination: Patients were clinically assessed by two qualified neurologist, and underwent general and neurological examinations. Neurological symptoms were recorded.

Imaging: Brain MRI was diagnosed by a radiologist and a neurologist, and results were recorded.

Surgery: The standard type of surgeries was eradication of necrotic brain tissue or cyst. Decompressive craniotomy was used to relieve the elevated intracranial pressure.

Histology: Pathological results for hematoxylin and eosin staining after surgery were recorded.

Outcome of surgery: The outcome at the end of six months after surgery was assessed according to LENT/ SOMA scales (late effects of normal tissue- subjective, objective, management, analytic) and modified Rankin scale.

Table 2 MRI characteristics in RI patients underwent surgery

\begin{tabular}{lcc}
\hline Brain MRI foci & Case number \\
\hline Multiple brain lobes & 7 \\
Temporal lobe & Bilateral & 7 \\
& Unilateral & 1 \\
Brain stem & 2 \\
Cyst & 9 \\
Mass effect and/or shift of the midline & 7 \\
\hline
\end{tabular}


Table 3 Type of surgical procedure

\begin{tabular}{lccc}
\hline Surgery & $\begin{array}{c}\text { Brain lesion } \\
\text { resection }\end{array}$ & $\begin{array}{c}\text { Decompressive } \\
\text { craniotomy }\end{array}$ & Total \\
\hline Case number & 13 & 2 & 15 \\
\hline
\end{tabular}

\section{Statistical analysis}

Multiple logistic regression was used to determine the association between age, gender, post-radiotherapy intervals, radiation dose, radiation field, brain MRI, surgery, pathology and clinical outcome. Testing was done at the 0.05 level of significance.

\section{Results}

\section{Individual characteristics}

The demographic data were summarized in Table 1. There were 15 patients with RI who were performed surgery, including $13(86.7 \%)$ males and 2 (13.3\%) females. The mean age was $50 \pm 9.0$ years, with a range of 28 to 65 years. The median interval between radiation and diagnosis of RI was 4 years, with a range of 0.5 to 13 years. The median interval between diagnosis of RI and surgery was 12 months, with a range of 3 to 144 months. The mean radiation dose was $83 \pm 28$ grays $(\mathrm{Gy})$, with a range of 66 to 138 Gy. Radiation field included faciocervical portal or preauricular portal, with a radio of 11:4. Three of 15 patients underwent reirradiation.

\section{Brain MR}

We performed brain MRI on these 15 RI patients. Areas of RI showed as prolonged $\mathrm{T} 2$ relaxation time in multiple brain lobes (46.7\%), bilateral temporal lobes (46.7\%), unilateral temporal lobe (6.7\%) and brain stem (13.3\%). As shown in Table 2, nine of 15 (60.0\%) patients underwent surgery showed cystic regions, and seven cases (46.7\%) showed mass effect and/or shift of the midline in the brain.

\section{Surgery and histology}

Brain lesion resection was taken in $86.7 \%$ patients, and decompressive craniotomy in $13.3 \%$ patients (Table 3 ). Three patients underwent emergency surgery due to significantly increased intracranial pressure, unconsciousness and signs of brain herniation. As shown in Table 4, the commonest pathology was brain necrosis (100\%), followed by gliosis $(76.9 \%)$ and small vascular proliferation (69.2\%). Haemorrhage (46.2\%), edema (23.1\%), and the infiltration of inflammatory cells $(7.7 \%)$ were also found in RI patients.

\section{Outcome}

The outcome was analyzed in the 15 RI patients who underwent surgery.

The post-operative follow-up ranged from 6 to 71 months. Two patients died at the endpoint (Table 1). LENT/SOMA scales and modified Rankin scale were evaluated before surgery and six months after surgery. As shown in Table 5, most cases showed improvement at subjective, objective, management and analytic domains, respectively. 12 of 15 patients showed improvement of modified Rankin scale after surgery. Three

Table 4 Pathology

\begin{tabular}{|c|c|c|c|c|c|c|}
\hline \multirow[t]{2}{*}{ Case } & \multicolumn{6}{|c|}{ Pathology } \\
\hline & Brain necrosis & Gliosis & Small vascular proliferation & Haemorrhage & Edema & Infiltration of inflammatory cells \\
\hline 1 & + & - & - & + & - & - \\
\hline 2 & + & + & + & + & - & - \\
\hline 3 & + & + & - & + & - & - \\
\hline 4 & + & + & + & - & - & - \\
\hline 5 & + & + & + & - & + & + \\
\hline 6 & + & + & - & - & - & - \\
\hline $7^{*}$ & - & - & - & - & - & - \\
\hline 8 & + & - & + & - & + & - \\
\hline 9 & + & + & + & + & - & - \\
\hline $10^{*}$ & - & - & - & - & - & - \\
\hline 11 & + & + & + & - & - & - \\
\hline 12 & + & + & + & + & - & - \\
\hline 13 & + & - & + & - & + & - \\
\hline 14 & + & + & + & + & - & - \\
\hline 15 & + & + & - & - & - & - \\
\hline Total & 13 & 10 & 9 & 6 & 3 & 1 \\
\hline
\end{tabular}

* These two cases were performed decompressive craniotomy and pathological results were not displayed. 
Table 5 Score increment of LENT/SOMA scales and modified Rankin scale before and after sugery

\begin{tabular}{llllll}
\hline Score Increment & & $\mathbf{+ 3}$ & $\mathbf{+ 2}$ & $\mathbf{+ 1}$ & $\mathbf{0}$ \\
\hline LENT SOMA (case number) & Subjective & 0 & 5 & 8 & 2 \\
& Objective & 2 & 3 & 7 & 3 \\
& Management & 3 & 6 & 5 & 1 \\
& Analytic & 5 & 7 & 2 & 1 \\
Rankin (case number) & & 0 & 5 & 7 & 3 \\
\hline
\end{tabular}

patients who underwent emergency surgery showed greater improvement (average score increment of 2, 2.7, 2.7, 3 and 2 at LENT/SOMA scale subjective, objective, management, analytic domains, and modified Rankin scale, respectively), as compared with 12 cases underwent elective surgery (average score increment of 1, 1, 1.4, 1.8 and 1 at LENT/SOMA scale subjective, objective, management, analytic domains, and modified Rankin scale, respectively). No significance was shown in the statistical analysis of the association between age, gender, post-radiotherapy intervals, radiation dose, radiation field, brain MRI, surgery, pathology and clinical outcome (Table 6).

\section{Discussion}

We have prospectively evaluated the therapeutic effectiveness of neurosurgery on radiation-induced brain injury. With respect to the scales evaluation before and after surgery, more than $80 \%$ patients achieved remission. Thus, our study indicated that neurosurgery intervention was beneficial as an invasive treatment. On the other hand, approximately $20 \%$ of our cases performed no improvement after surgery. The latter observation was likely due to unremitting cognitive impairment. No significance was shown in the statistical analysis of the association between individual characteristics, brain MRI, surgery, pathology and clinical outcome. This might be limited by the small sample size.

The patients who experienced recurrence of NPC would be retreated with a second course of radiotherapy. Whole brain reirradiation was reported to cause acute adverse reactions in more than $70 \%$ of patients [8]. Three cases of our patients suffered with NPC recurrence, and were administered with a second course of radiation. Severe brain injuries, shown as massive foci in multiple lobes of the brain and transtentorial herniation, occurred in these three patients shortly after reirradiation. One case was diagnosed with RI three months after reirradiation,

Table 6 Multiple logistic regression analysis of age, gender, post-RT intervals, radiation dose, radiation field, brain MRI, surgery, pathology to predict clinical outcome

\begin{tabular}{|c|c|c|c|c|}
\hline \multicolumn{2}{|l|}{ Variables } & Score & Degree of freedom & $P$ value \\
\hline \multicolumn{2}{|l|}{ Age } & 1.799 & 1 & 0.180 \\
\hline \multicolumn{2}{|l|}{ Gender } & 2.685 & 1 & 0.101 \\
\hline \multicolumn{2}{|c|}{ Interval 1 (year) ${ }^{1}$} & 2.671 & 1 & 0.102 \\
\hline \multicolumn{2}{|c|}{ Interval 2 (month) ${ }^{2}$} & 1.057 & 1 & 0.304 \\
\hline \multicolumn{2}{|c|}{ Radiation dose (Gy) } & 0.774 & 1 & 0.379 \\
\hline \multicolumn{2}{|l|}{ Radiation field } & 0.839 & 1 & 0.360 \\
\hline \multicolumn{2}{|l|}{ Surgery } & 0.355 & 1 & 0.551 \\
\hline \multirow[t]{6}{*}{ Brain MRI foci } & Multiple brain lobes & 2.637 & 1 & 0.104 \\
\hline & Bilateral temporal lobes & 2.019 & 1 & 0.155 \\
\hline & Unilateral temporal lobe & 0.165 & 1 & 0.685 \\
\hline & Brain stem & 0.355 & 1 & 0.551 \\
\hline & Cyst & 3.462 & 1 & 0.063 \\
\hline & Mass effect and/or shift of the midline & 2.637 & 1 & 0.104 \\
\hline \multirow[t]{6}{*}{ Pathology } & Brain necrosis & 0.709 & 1 & 0.400 \\
\hline & Gliosis & 0.410 & 1 & 0.522 \\
\hline & Small vascular proliferation & 2.026 & 1 & 0.155 \\
\hline & Haemorrhage & 0.709 & 1 & 0.400 \\
\hline & Edema & 0.197 & 1 & 0.657 \\
\hline & Infiltration of inflammatory cells & 5.318 & 1 & 0.378 \\
\hline
\end{tabular}

Dependent: clinical outcome (survival or died).

${ }^{1}$ Interval between radiation and diagnosis of RI (for the patients who underwent reirradiation, this was the interval between reirradiation and diagnosis of RI).

2 Interval between diagnosis of RI and surgery. 
and underwent surgery five months after diagnosis of RI, the other two showed severe headache, disturbance of consciousness, and obvious foci in brain MRI within one month after reirradiation, and underwent surgery about one year later. Mou et al. reported 14 cases of RI who underwent neurosurgery treatment, and found that the mean latency of radiation-induced brain necrosis in patients with reirradiation was much shorter than that with one course radiation [9]. Radiation-induced normal brain tissue necrosis is found to commonly occur at the cumulative normalized total dose of $>100$ Gy [10]. Thus, reirradiation increased the incidences of normal brain necrosis and edema, and might increase the probability of emergency surgery other than elective surgery. Moreover, clinical and scoring evaluation showed significant improvement after emergency surgery.

For patients with RI after NPC radiotherapy, surgery is considered to be the last resort for those who with poorcontrolled conditions, e.g. progressive symptoms despite conservative therapy, hemorrhage, and brain necrosis formation $[7,11]$. In this study, the emergency surgery was performed in three patients who showed significantly increased intracranial pressure, unconsciousness, signs of brain herniation at admission, and the critical symptoms could not be alleviated quickly by conservative methods. With regard to elective surgery, indications and selections of operation time should be evaluated with more caution. Twelve of our 15 cases underwent elective surgery. The indications for elective neurosurgery included severe brain edema and necrosis (8 of 15), severe symptoms e.g. headache, disturbance of consciousness (5 of 15), and hemorrhage (1 of 15), and full-course medication, including intravenous corticosteroids, could not relieved these symptoms. There was one case in our study performed neurosurgery due to a misdiagnosis. The initial diagnosis based on imaging was metastasis of NPC. To be certain, differentiating this condition from brain tumor remains a challenge [12]. The differential diagnoses of RI include intracranial extension of NPC, second primary intracranial neoplasm, cerebral metastasis, meningeal spread and brain abscess [13]. Presently, MRI scan is commonly used for diagnosis of RI, and was sensitive in revealing radiation damage of the brain [14]. However, a definitive diagnosis cannot be obtained from MRI, or other imaging tools, e.g. $\mathrm{CT}$ and PET-CT. In brain imaging, both malignant lesions and radiation-induced injuries showed as marked vasogenic edema, mass effect, and ring-enhancing patterns $[15,16]$. Advanced imaging methods and computer technology, including diffusion-weighted magnetic resonance imaging, perfusion magnetic resonance imaging, and proton magnetic resonance spectroscopic imaging, would help to narrow the differential possibilities $[7,17,18]$. However, a definitive diagnosis of cancer still needed morphology. Furthermore, the MRI of our misdiagnosed patient presented brain lesion in the occipital and frontal lobes instead of the temporal lobe. This could be another cause of diagnostic dilemma.

\section{Conclusions}

In summary, we observed the MRI imaging, surgical treatment, histology and prognosis in RI patients after radiotherapy of NPC who underwent neurosurgery. Our observation found that neurosurgery, including brain necrotic tissue resection and decompressive craniotomy, improved the prognosis for RI patients, especially for those with indications of emergency surgery.

\section{Abbreviations \\ NPC: Nasopharyngeal carcinoma; Rl: Radiation-induced brain injury; $M R I$ : Magnetic resonance imaging.}

\section{Competing interests}

The authors have no conflict of interest.

\section{Authors' contributions}

YT designed this study, carried out the collection and the follow-up of all the patients, and drafted the manuscript. YL and XS carried out the collection and the follow-up of all the patients, performed the evaluation of scales and the statistical analysis, and drafted the manuscript. SR participated in the follow-up of all the patients, helped to perform the evaluation of scales. YP participated in the design of the study and coordination and helped to draft the manuscript. All authors read and approved the final manuscript.

\section{Acknowledgements}

This work was supported by National Natural Science Foundation of China (No. 81072242, and No. 81272576) to Y. Tang, Natural Science Foundation of Guangdong Province (No. S2011010004708) to Y. Tang, Funds for Pearl River Science \& Technology Star of Guangzhou City (2012 J2200088) to Y. Tang, National Natural Science Foundation of China (No. 81200922) to Y. Li, Natural Science Foundation of Guangdong Province (S2011010004615) to Y. Li, Sun Yat-Sen Scholarship for Young Scientists to Y. Li.

Received: 21 October 2012 Accepted: 20 March 2013

Published: 11 April 2013

\section{References}

1. Ho JH: An epidemiologic and clinical study of nasopharyngeal carcinoma. Int J Radiat Oncol Biol Phys 1978, 4:183-205.

2. Crossen JR, Garwood D, Glatstein E, Neuwelt EA: Neurobehavioral sequelae of cranial irradiation in adults: a review of radiation-induced encephalopathy. J Clin Oncol 1994, 12:627-642.

3. Genc M, Genc E, Genc BO, Kiresi DA: Significant response of radiation induced CNS toxicity to high dose steroid administration. Br J Radiol 2006, 79:e196-e199.

4. Shalev O, Silverberg R: Dexamethasone for acute radiation encephalopathy. Lancet 1978, 2:574-575.

5. Hu JQ, Guan YH, Zhao LZ, Xie SX, Guo Z, Liang ZH: Delayed radiation encephalopathy after radiotherapy for nasopharyngeal cancer: a CT study of 45 cases. J Comput Assist Tomogr 1991, 15:181-187.

6. Tang $Y$, Shen $Q$, Wang $Y$, Lu K, Wang $Y$, Peng $Y$ : A randomized prospective study of rehabilitation therapy in the treatment of radiation-induced dysphagia and trismus. Strahlenther Onkol 2011, 187:39-44.

7. Chen J, Dassarath M, Yin Z, Liu H, Yang K, Wu G: Radiation induced temporal lobe necrosis in patients with nasopharyngeal carcinoma: a review of new avenues in its management. Radiat Oncol 2011, 6:128.

8. Son CH, Jimenez R, Niemierko A, Loeffler JS, Oh KS, Shih HA: Outcomes after whole brain reirradiation in patients with brain metastases. Int $\mathrm{J}$ Radiat Oncol Biol Phys 2012, 82:e167-e172.

9. Mou YG, Sai K, Wang ZN, Zhang XH, Lu YC, Wei DN, Yang QY, Chen ZP: Surgical management of radiation-induced temporal lobe necrosis in patients with nasopharyngeal carcinoma: report of 14 cases. Head Neck 2011, 33:1493-1500. 
10. Mayer R, Sminia P: Reirradiation tolerance of the human brain. Int I Radiat Oncol Biol Phys 2008, 70:1350-1360

11. Hsu YC, Wang LF, Lee KW, Ho KY, Huang CJ, Kuo WR: Cerebral radionecrosis in patients with nasopharyngeal carcinoma. Kaohsiung J Med Sci 2005, 21:452-459.

12. Dassarath M, Yin Z, Chen J, Liu H, Yang K, Wu G: Temporal lobe necrosis: a dwindling entity in a patient with nasopharyngeal cancer after radiation therapy. Head Neck Oncol 2011, 3:8.

13. Glass JP, Hwang TL, Leavens ME, Libshitz HI: Cerebral radiation necrosis following treatment of extracranial malignancies. Cancer 1984, 54:1966-1972.

14. Lee AW, Cheng LO, Ng SH, Tse VK, O SK, Au GK, Poon YF: Magnetic resonance imaging in the clinical diagnosis of late temporal lobe necrosis following radiotherapy for nasopharyngeal carcinoma. Clin Radiol 1990, 42:24-31.

15. Wang YX, King AD, Zhou H, Leung SF, Abrigo J, Chan YL, Hu CW, Yeung DK, Ahuja AT: Evolution of radiation-induced brain injury: MR imaging-based study. Radiology 2010, 254:210-218

16. Young RJ, Knopp EA: Brain MRI: tumor evaluation. J Magn Reson Imaging 2006, 24:709-724.

17. Cha S: Update on brain tumor imaging. Curr Neurol Neurosci Rep 2005, 5:169-177.

18. Lemort M, Canizares-Perez AC, Van der Stappen A, Kampouridis S: Progress in magnetic resonance imaging of brain tumours. Curr Opin Oncol 2007, 19:616-622.

doi:10.1186/1748-717X-8-88

Cite this article as: Li et al:: Neurosurgery and prognosis in patients with radiation-induced brain injury after nasopharyngeal carcinoma

radiotherapy: a

follow-up study. Radiation Oncology 2013 8:88.

\section{Submit your next manuscript to BioMed Central and take full advantage of:}

- Convenient online submission

- Thorough peer review

- No space constraints or color figure charges

- Immediate publication on acceptance

- Inclusion in PubMed, CAS, Scopus and Google Scholar

- Research which is freely available for redistribution 